\title{
Experimental investigation of the charge/discharge process for an organic PCM macroencapsulated in an aluminium rectangular cavity
}

\author{
Andrei-Stelian Bejan ${ }^{1, *}$, Abdelouhab Labihi ${ }^{1,3}$, Cristiana Verona Croitoru ${ }^{1,2}$, Tiberiu Catalina ${ }^{1,2}$,Hassan Chehouani $^{3}$ and \\ Brahim Benhamou, ${ }^{4,5}$ \\ ${ }^{1}$ Technical University of Civil Engineering Bucharest, Faculty of Engineering for Building Services, 021407 Bucharest, Romania \\ ${ }^{2}$ CAMBI Research Center, 021407 Bucharest, Romania \\ ${ }^{3}$ Laboratory of Processes, Metrology, Materials for Energy and Environment (LP2M2E), Faculty of Sciences and Techniques, Cadi \\ Ayyad University, Marrakech, Morocco \\ ${ }^{4}$ Laboratoiry of Renewable Energies and Energy Efficiency (EnR2E), National Center of Studies and Research on Water \& Energy \\ (CNEREE), Cadi Ayyad University, Marrakech, Morocco \\ ${ }^{5}$ Energy Process Research Group at LMFE, Faculty of Sciences Semlalia, Cadi Ayyad University, Marrakech, Morocco
}

\begin{abstract}
Buildings sector has one of the highest potential regarding the reduction of greenhouse gases emissions, as being responsible for more than $40 \%$ of energy consumption worldwide. This is why, in order to achieve indoor thermal comfort, it is mandatory to use energy-efficient systems. Materials acting as thermal energy storage (TES) represents one of the most effective strategy that can be implemented and nowadays, many studies are focusing their attention on latent heat storage, respectively on phase changing materials (PCM) which can embed a large embed a high quantity of energy, unlike classic materials acting as thermal mass. This purpose of this paper is to experimentally investigate the charge and discharge processes for an organic PCM (RT35 paraffin) macroencapsulated in an aluminium rectangular cavity which was placed first in a horizontal position and after in a vertical position. After several experimental campaigns conducted we determined that the vertical position enhance the heat transfer because of the natural convection which occurs inside the cavity. Therefore, the charging time is lower in case of the vertical cavity and the temperature measured inside and on the surface is higher.
\end{abstract}

\section{Introduction}

\subsection{Context and motivation}

According to the United Nations Environment Programme [1] building sector has the highest potential regarding the reduction of greenhouse gases emissions around the world, with relative low investment costs. Moreover, the building sector is responsible for more than $40 \%$ of energy consumption and $33 \%$ of greenhouse gases emissions worldwide.

Furthermore, all the members of the United Nations (196 states) have, after the COP21 conference (which took place in 2015 in Paris, France), a common goal: to limit the global warming at $2{ }^{\circ} \mathrm{C}$ above preindustrial era [2] which imposes even more stringent requirements and regulations regarding energy consumption in buildings, buildings envelope and buildings systems.

In Europe, more than $50 \%$ of the energy consumption in buildings is due to the HVAC systems that ensure the indoor thermal comfort and indoor air quality [3]. Moreover, an important percentage of the total amount of energy consumption is due to the fresh air needed by the buildings occupants and approximately $20-50 \%$ of the energy consumption for heating and cooling is due to the building envelope [4]. Also, all these values percentages have an ascending trend in all the developed countries [5].

In order to reduce energy consumptions and $\mathrm{CO}_{2}$ emissions determined by the buildings sector it is very important to implement innovative materials and energy efficient systems using renewable energy sources.

\subsection{Latent heat thermal energy storage (LHTES)}

Thermal energy storage (TES) materials represent one of the most promising methods of reducing energy consumptions in buildings by incorporating them into passive systems and active systems $[6,7]$.

TES materials can be classified by taking into account the storage method as: sensible heat storage, latent heat storage and chemical heat storage [8]. One of the most promising materials used in order to store latent heat are the phase changing materials (PCMs) because they can store 5-14 times more energy than classical materials $[9,10]$. According to Soares et al. [9], PCMs integrated in building envelope or building systems could determine the following benefits:

\footnotetext{
* Corresponding author: andrei.s.bejan@gmail.com
} 
- Lower energy consumption for heating and cooling

- Lower operating costs and $\mathrm{CO}_{2}$ emissions

- Lower heating and cooling loads (undersized systems)

- Better performance of building envelope

- Better thermal comfort (fewer overheating hours, lower temperature variations).

Phase changing materials is a TES medium that draws the attention of many researchers over the last decade [11, 12] and according to Navarro et al. [6] these materials can improve the overall efficiency of systems using renewable energy sources by storing the surplus energy and using it during the periods when the source is not available (e.g. during night-time in case of solar radiation).

There are several types of PCMs studied in literature [6, 7, 13, 14]: organic PCMs, inorganic PCMs (salt hydrates) and eutectics. The organic PCMs (usually paraffin) are one of the most used in the building sector because their characteristics: large storage capacity, phase change temperature within the comfort limits, market availability, low-cost and because they are nontoxic. According to many researchers, the most important properties that must be taken into account when choosing the type of PCM are [15-17]: phase change temperature (near to the operating value), high thermal conductivity, large storage capacity, low volume variations, good thermal stability in time, high specific heat etc..

PCMs can be microencapsulated an macroencapsulated [18]. In case of microencapsulation the bulk material is embedded in capsules with a very small diameter (less than $1 \mathrm{~mm}$ ), while in case of macroencapsulation the bulk materials is embedded in different types of containers (e.g. metal panels, spheres, cylinders, tubes etc.) [19].

\subsection{Charge/discharge problem}

According to the literature the main problem in case of organic PCM is that the thermal conductivity has low values (approximately $0.2 \mathrm{~W} / \mathrm{mK}$ for paraffin) [17]. There are many strategies that can be used in order to improve the heat transfer $[13,15,17]$ : the use of materials with high thermal conductivity (graphite, aluminium or copper matrixes, metal particles, carbon fibres), the use of metal structures for macroencapsulation (metal spheres, metal rings, metal fins inside or outside the cavity, rectangular or cylindrical tubes) and the use of metal containers for microencapsulation (small iron spheres, metal cylinders).

According to Iten and Liu [20], in order to choose the proper container it is important to know: details about the application and available space, boundary conditions and the contact material. Same authors emphasise that usually the metal containers are used in order to improve the heat transfer (especially aluminium, steel and copper) and moreover, the rectangular containers are being used often because of easy manufacturing and high storage density of PCM (up to $90 \%$ of the total volume). Not only the geometry and material is important when choosing the PCM and related container, but also the position relative to the vertical direction [21] which has a determinant role regarding the thermal transfer processes and can improve the natural convection issues inside the cavity [22].

This paper aims to study in an experimental manner the charge and discharge process for an organic PCM macroencapsulated in an aluminium rectangular cavity which can be used in different building applications and especially in solar air collectors, building walls, or building systems.

\section{Experimental setup}

\subsection{Materials and methods}

Figure 1 shows the aluminium rectangular tube which was used as a container for the PCM. The tube has the following dimensions: $800 \times 60 \times 20 \mathrm{~mm}$ (2mm thickness) and it was filled with approximately 0.91 of paraffin (macroencapsulation). After this stage it was sealed with special glue, painted in black and covered with $2.5 \mathrm{~mm}$ of insulation on all sides (except the one exposed to the heat source). In order to cope with the volume changes during the phase change, one very small hole was made in one corner of the tube.
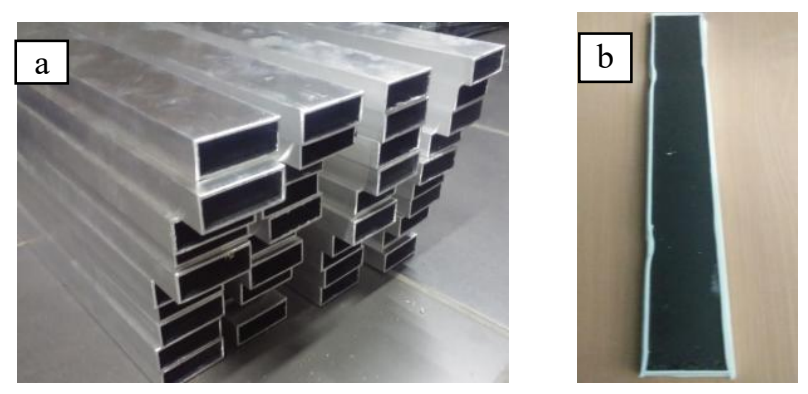

Fig. 1. Aluminium rectangular tube: a-empty, b-filled with PCM and prepared for experimental study
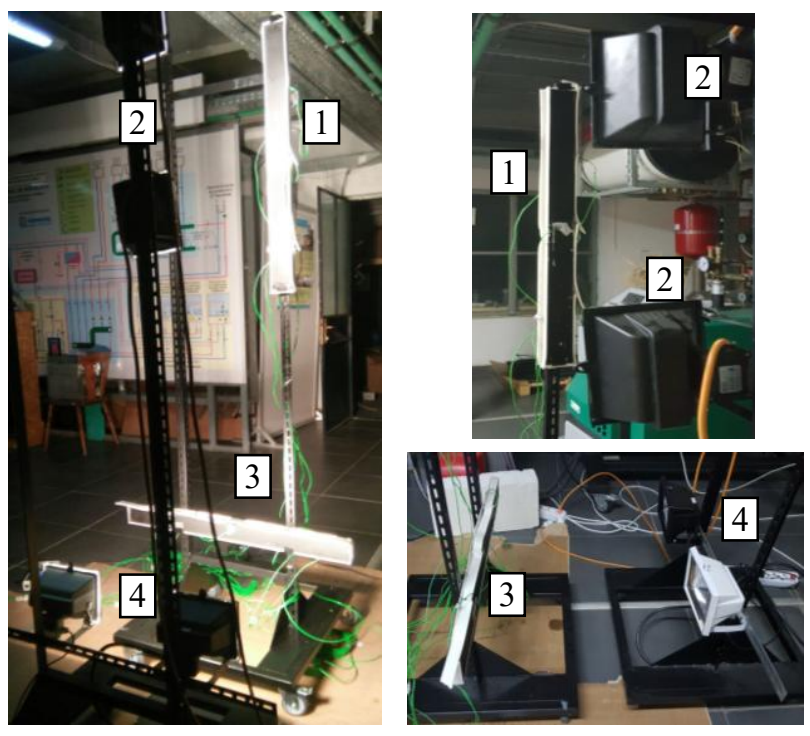

Fig. 2. Experimental setup: 1-vertical tube, 2-lamps for vertical tube, 3-horizontal tube and 4-lamps for horizontal tube 
The experimental setup considers two rectangular tubes: one mounted vertical and one mounted horizontal. Every bar is heated by two halogen lamps (500W each) placed on a stand at $500 \mathrm{~mm}$ distance, which ensures a uniform heat distribution on each tube.

The organic PCM used for the experimental study was bulk paraffin RT35 with the phase changing temperature around $35^{\circ} \mathrm{C}$. All thermal properties of the RT35 are presented in table 1 .

Table 1. PCM RT35 properties

\begin{tabular}{|c|c|c|}
\hline Data & Value & Unit \\
\hline Melting area & $29-36$ & ${ }^{\circ} \mathrm{C}$ \\
\hline Congealing area & $36-31$ & ${ }^{\circ} \mathrm{C}$ \\
\hline Heat storage capacity & 160 & $\mathrm{~kJ} / \mathrm{kg}$ \\
\hline Specific heat capacity & 2 & $\mathrm{~kJ} / \mathrm{kgK}$ \\
\hline Density solid (at $\left.15^{\circ} \mathrm{C}\right)$ & 0.86 & $\mathrm{~kg} / 1$ \\
\hline Density liquid $\left(\right.$ at $\left.45^{\circ} \mathrm{C}\right)$ & 0.77 & $\mathrm{~kg} / 1$ \\
\hline Heat conductivity & 0.2 & $\mathrm{~W} / \mathrm{mK}$ \\
\hline
\end{tabular}

\subsection{Measurement procedure}

In order to study the charge/discharge process in case of RT35 PCM macroencapsulated in the rectangular cavity, two aluminium bars were used. Inside each tube, three K-type thermocouples with accuracy of $0.2^{\circ} \mathrm{C}$ were mounted at $200 \mathrm{~mm}$ distance, in order to measure the temperature in the cavity in different points $\mathrm{x} 20, \mathrm{x} 40$ and $\mathrm{x} 60$ for the horizontal bar and y20, y40 and y60 for the vertical bar). Another two thermocouples were placed on the surface of each aluminium bar in order to measure the surface temperature in the middle of the container. One more thermocouple was used to measure the ambient temperature.

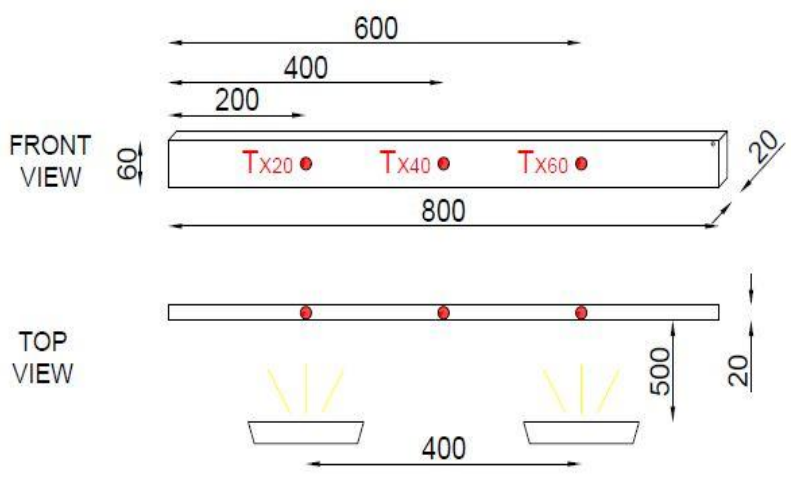

Fig. 3. Dimensions and placement of the sensors - horizontal tube

The measurements were conducted for 21 hours, temperature values were recorded every 5 minutes and all the data was collected using a very precise data logger. Moreover, we used the FLIR-E40 thermal imaging camera in order to measure the surface temperature after two hours of charge and two hours of discharge (correlation with thermocouple and the temperatures inside the cavity). Both devices are presented in figure 5 .

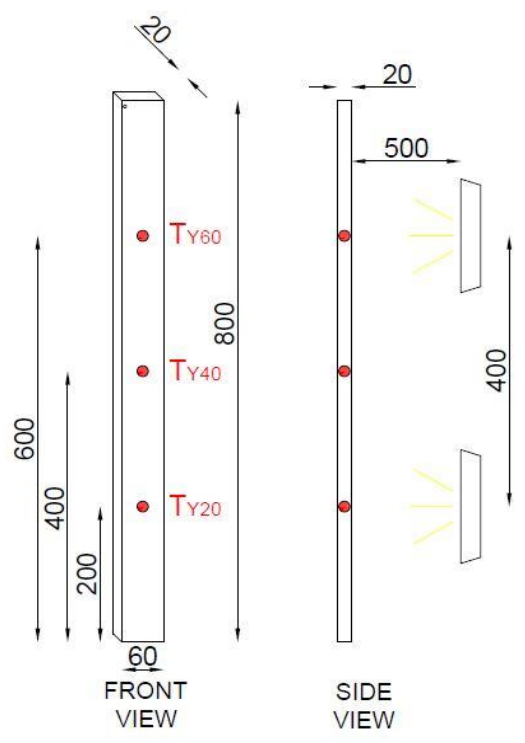

Fig. 4. Dimensions and placement of the sensors - vertical tube
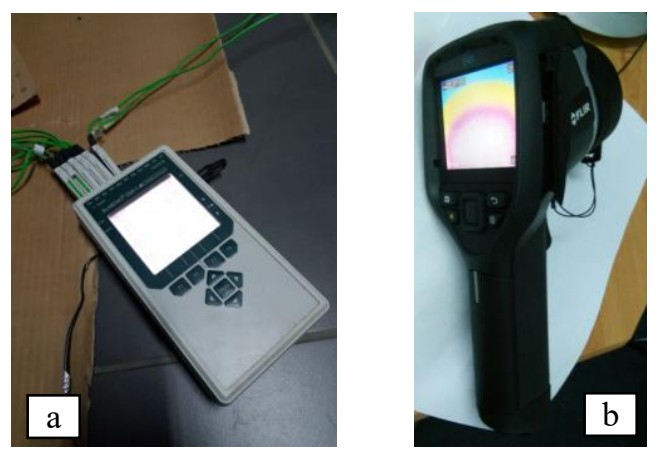

Fig. 5. Data logger (a) and thermal imaging camera (b)

\section{Results}

\subsection{Analysis of charge/discharge}

Following the experimental studies conducted we obtained very interesting results. The measurements were made in similar conditions for both vertical and horizontal rectangular aluminium containers with PCM.

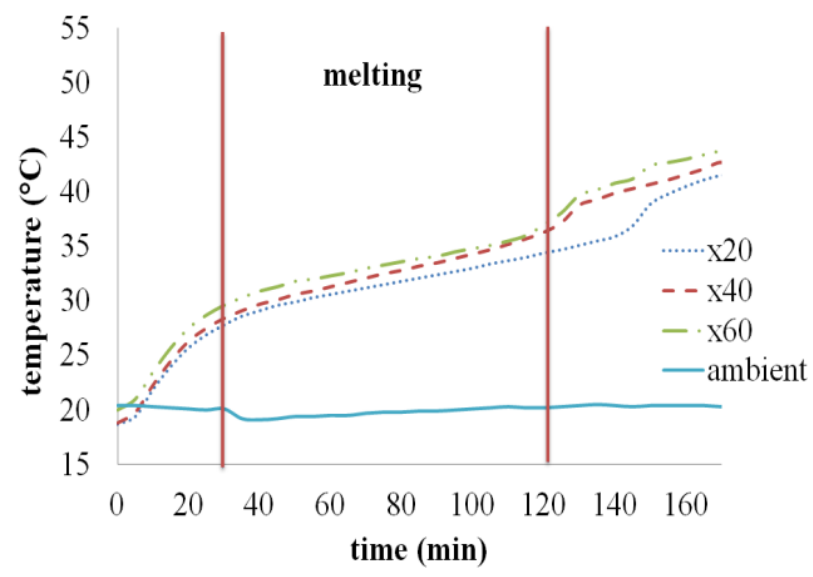

Fig. 6. Charging - horizontal rectangular tube

Figure 6 shows the charging process for the horizontal rectangular tube filled with organic PCM. The 
process has three stages: solid state (storing sensible heat), mixture (storing latent and sensible heat while melting) and liquid state (storing sensible heat). The melting period starts after 30 minutes and it takes approximately 90 minutes to change phase from solid to liquid mainly because of thermal conduction. During the charging period, the PCM transforms to liquid state after 120 minutes and reaches the maximum temperature of $43.6^{\circ} \mathrm{C}$ after 170 minutes. Because of the enhanced thermal conductivity determined by the aluminium material, the heat is evenly distributed to PCM, with minimal heat losses. This phenomenon determines only small differences between the values measured by the thermocouples in different points in the rectangular cavity (up to $1.8^{\circ} \mathrm{C}$ ).

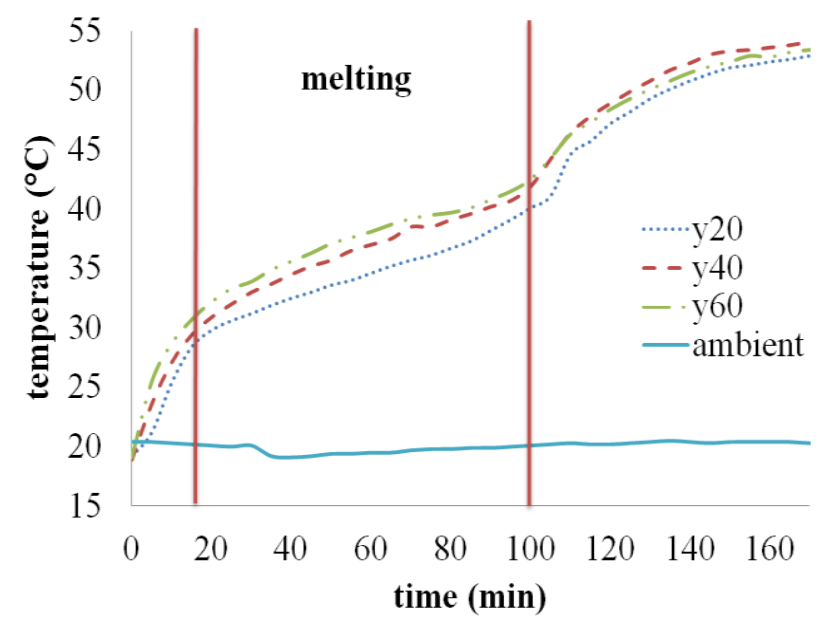

Fig. 7. Charging - vertical rectangular tube

Figure 7 shows the charging process in case of the vertical rectangular tube filled with organic PCM, experimentally studied in the same conditions of ambient temperature and radiation (from the heat source) as the horizontal one. However, the results emphasise important differences. The melting stage starts after 18 minutes, much faster than in the first case and it takes approximately 80 minutes to change phase from solid to liquid. During the charging period the PCM transforms to liquid state after 98 minutes, reaches $43.6^{\circ} \mathrm{C}$ after 110 minutes (60 minutes faster) and after 170 minutes achieves the maximum temperature of $54.6^{\circ} \mathrm{C}\left(11^{\circ} \mathrm{C}\right.$ more). In case of the vertical cavity, because of the high thermal conductivity of aluminium and the evenly distributed heat he PCM begins to melt near the cavity walls and all the liquid paraffin goes in the upper part of the rectangular cavity. This is why we can observe even $3.5^{\circ} \mathrm{C}$ difference between $\mathrm{T}_{\mathrm{Y} 20}$ and $\mathrm{T}_{\mathrm{Y} 60}$. This stratification inside the cavity is due to the fact that, besides the conduction phenomena, an important role is fulfilled by the natural convection inside the cavity, as mentioned before in different studies [20, 21, 23].

Figure 8 shows the discharging process for the horizontal rectangular tube. The process has three stages: liquid state (releasing sensible heat), mixture (releasing sensible and latent heat while solidifying) and solid state (releasing sensible heat, stabilizing to ambient temperature). The sensible heat during the liquid state is discharged quickly and after only 15 minutes the PCM begins to solidify. The solidification lasts for about 165 minutes, although the phenomenon is not so obvious (the evolution of the discharging curve changes around the $350^{\text {th }}$ minute of the experimental campaign).

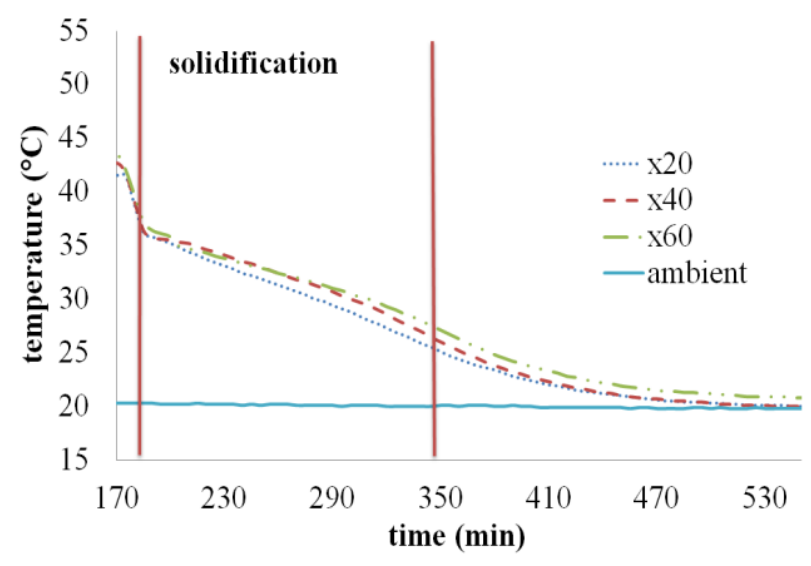

Fig. 8. Discharging - horizontal rectangular tube

Figure 9 shows the discharging process in case of the vertical rectangular tube, also in the same conditions of ambient temperature as in the previous case. The sensible heat during the liquid state is release slower because the temperature of PCM is higher, but after 30 minutes the PCM begins to solidify. The stratification in case of discharging is no longer clear as in the case of charging process because the PCM begins to solidify near to the aluminium wall. Because of the good conductivity of aluminium the solidification inside the cavity is uniform until the moment when temperature measured by thermocouple $\mathrm{T}_{\mathrm{Y} 20}$ drops suddenly $\left(275^{\text {th }}\right.$ minute) which means that an important amount of solid PCM gathered in the lower part of the vertical cavity and this phenomena enhance the convective transfer within the cavity. The solidification process lasts for about 135 minutes, although the phenomenon is not so obvious, similar with the previous case.

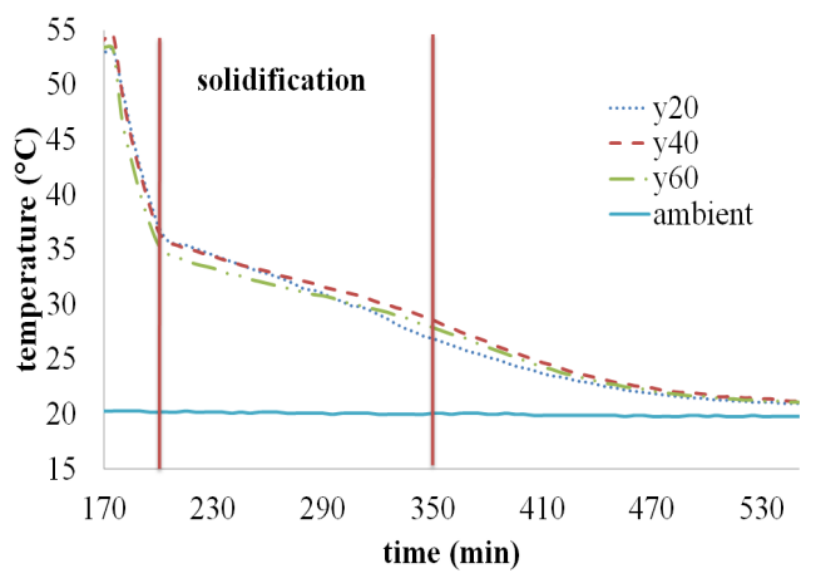

Fig. 9. Discharging - vertical rectangular tube

\subsection{Analysis of surface temperature}

Because of a lower charging period in case of the vertical cavity, the temperature on the surface of 
aluminium rectangular tube is also higher. This determines also an enhanced convective transfer between the vertical PCM filled bar and ambient air that can explain the fast heat release in the first stage of the discharging process.

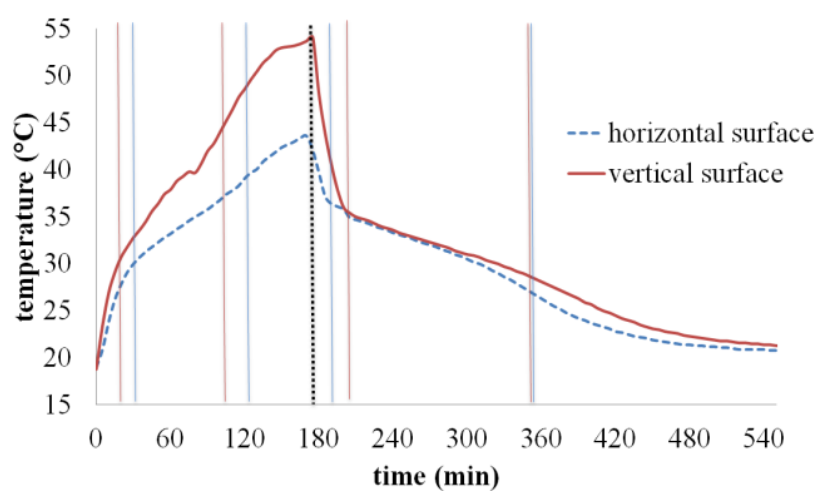

Fig. 10. Variation of surface temperature during charging and discharging

This phenomena is emphasised by figure 10 and also by thermal images presented in figure 11 and figure 12 .

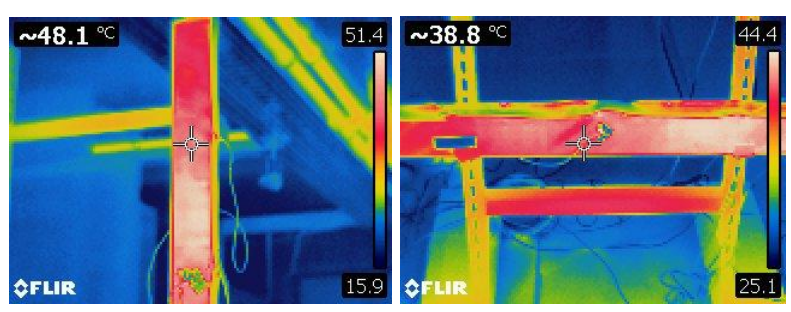

Fig. 11. Thermal images after two hours of charging

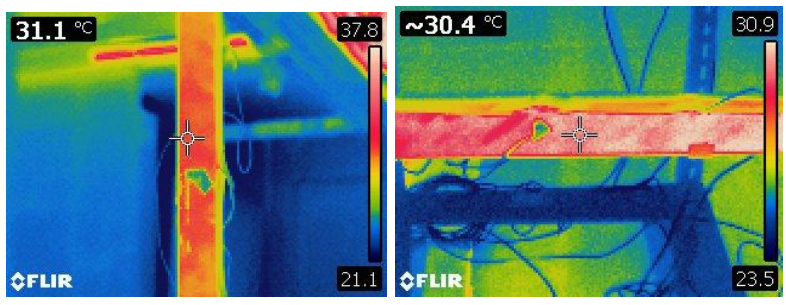

Fig. 12. Thermal images after two hours of discharging

\section{Conclusions}

In the current context (high energy consumptions and $\mathrm{CO}_{2}$ emissions determined by the building sector) it is essential to implement highly efficient systems using renewable energy sources and innovative materials. Nowadays, many researches focus their attention on the latent heat thermal energy storage, such as phase changing materials which can determine important benefits regarding achieving indoor thermal comfort with minimum energy consumption.

This paper aims to evaluate in an experimental manner the charging and discharging phenomena for an organic PCM (RT 35 paraffin) macroencapsulated in an aluminium rectangular cavity. After several experimental studies conducted we can conclude that:

- The charging time in case of a vertical aluminium tube filled with PCM is lower, unlike the horizontal position
- The stratification inside the vertical cavity is easy to observe during the charging period, but not so obvious during the discharge process

- During charging process the thermal transfer in enhanced in case of the vertical tube due to the convective transfer (in addition to conductive transfer which is predominant in the case of the horizontal tube) - The aluminium distributes uniform the heat towards the PCM because of high conductivity

- After 170 minutes of charging the maximum temperature inside the vertical cavity reaches $54.6^{\circ} \mathrm{C}$, unlike $43.6^{\circ} \mathrm{C}$ in case of the horizontal cavity

- The $43.6^{\circ} \mathrm{C}$ temperature is achieved after only 110 minutes in case of vertical cavity (60 minutes faster)

- The discharging period is longer than the charging period, similar with other studies from the literature

- The discharging period is similar in both cases and the convective transfer is not so clear during this stage

- The surface temperature is higher in case of vertical cavity which enhance the convective transfer between the aluminium bar and ambient air.

Further studies will be conducted in order to better understand the complex phenomena which occurs inside the aluminium rectangular cavity filled with organic PCM. The charge and discharge will be also studied in transparent cavities with different thicknesses in order to assess the impact of geometry. Other types of phase changing materials with different phase changing temperatures will be investigated. Moreover, the studied bars will be used in several building elements and systems in order to assess the impact of PCM implementation in terms of energy savings and improvement of indoor thermal comfort. One the main studies which will be conducted by authors of the present paper will investigate the implementation of thermal energy storage in a transpired solar collector (with air), which acts as a solar wall. In this case, the implementation of latent heat storage can improve the overall efficiency of the system by lagging the solar energy stored during the periods when the solar radiation is available (e.g. during day-time) and using it during periods when solar radiation is not available (e.g. during night-time, when the heat will be slowly released to the air).

This work was supported by a grant of the Romanian National Authority for Scientific Research, CNCS - UEFISCDI, project number PN-III-P2-2.1-PED-2016-1154.

\section{References}

1. UNEP, Buildings and Climate Change Summary for Decision-Makers. (United Nations Environment Programme - Sustainable Buildings \& Climate Initiative, 2009)

2. G. Rajgor, Renewable Energy Focus 17, 175-177 (2016)

3. M. Saffari, A. de Gracia, S. Ushak, and L.F. Cabeza, Energy and Buildings 112, 159-172 (2016)

4. T. Zhang, Y. Tan, H. Yang, and X. Zhang, Applied Energy 165, 707-734 (2016) 
5. P. Kumar and L. Morawska, Environmental Science \& Technology 47, 7591-7592 (2013)

6. L. Navarro, A. de Gracia, S. Colclough, M. Browne, S.J. McCormack, P. Griffiths, and L.F. Cabeza, Renewable Energy 88, 526-547 (2016)

7. L. Navarro, A. de Gracia, D. Niall, A. Castell, M. Browne, S.J. McCormack, P. Griffiths, and L.F. Cabeza, Renewable Energy 85, 1334-1356 (2016)

8. T. Khadiran, M.Z. Hussein, Z. Zainal, and R. Rusli, Renewable and Sustainable Energy Reviews 57, 916-928 (2016)

9. N. Soares, J.J. Costa, A.R. Gaspar, and P. Santos, Energy and Buildings 59, 82-103 (2013)

10. A. Kylili and P.A. Fokaides, Journal of Building Engineering 6, 133-143 (2016)

11. C. Liu, C. Wang, Y. Li, and Z. Rao, RSC Advances 7, 7238-7249 (2017)

12. S.N. Al-Saadi and Z. Zhai, Renewable and Sustainable Energy Reviews 21, 659-673 (2013)

13. S.A. Memon, Renewable and Sustainable Energy Reviews 31, 870-906 (2014)

14. S.E. Kalnæs and B.P. Jelle, Energy and Buildings 94, 150-176 (2015)

15. A. Waqas and Z. Ud Din, Renewable and Sustainable Energy Reviews 18, 607-625 (2013)

16. V.V. Tyagi and D. Buddhi, Renewable and Sustainable Energy Reviews 11, 1146-1166 (2007)

17. D. Zhou, C.Y. Zhao, and Y. Tian, Applied Energy 92, 593-605 (2012)

18. Y. Konuklu, M. Ostry, H.O. Paksoy, and P. Charvat, Energy and Buildings 106, 134-155 (2015)

19. L.F. Cabeza, A. Castell, C. Barreneche, A. de Gracia, and A.I. Fernández, Renewable and Sustainable Energy Reviews 15, 1675-1695 (2011)

20. M. Iten and S. Liu, Energy Conversion and Management 77, 608-627 (2014)

21. A. Baïri, E. Zarco-Pernia, and J.M. García de María, Applied Thermal Engineering 63, 304-322 (2014)

22. A.I.N. Korti and F.Z. Tlemsani, Journal of Energy Storage 5, 177-186 (2016)

23. A. Labihi, F. Aitlahbib, H. Chehouani, B. Benhamou, M. Ouikhalfan, C. Croitoru, and I. Nastase, Applied Thermal Engineering 126, 305314 (2017) 